\title{
Velorios, santos y marimbas en el Museo Nacional de Colombia: ¿de quién es el patrimonio de la Nación? ${ }^{1}$
}

\author{
Juliana Botero Mejía ${ }^{2}$ \\ Investigadora independiente \\ julianaboterom@yahoo.com \\ Sofia Natalia González Ayala ${ }^{3}$ \\ Universidad de Manchester, Manchester, Reino Unido ${ }^{4}$ \\ sngonzaleza@gmail.com
}

Recibido: 23 de julio de 2013

Aceptado: 9 de septiembre de 2013

\footnotetext{
Artículo de reflexión con base en la experiencia laboral e investigativa previa de las autoras, entrevistas, revisión de literatura académica, prensa y documentos oficiales. Sofia Natalia González realiza este escrito mientras hace el trabajo de campo para su investigación doctoral en la Universidad de Manchester, titulada "Comunidades negras, afrocolombianas, raizales y palenqueras en el Museo Nacional de Colombia: una aproximación desde la antropología visual y reflexiva", con financiación de Colciencias. Sin embargo, aunque las reflexiones del presente artículo se relacionan con este proyecto, no constituyen un avance de investigación del mismo.

2 Antropóloga de la Universidad Nacional de Colombia. Magíster en Antropología social y etnografia de la École des Hautes Études en Sciences Sociales de París, Francia.

3 Antropóloga de la Universidad Nacional de Colombia.

4 Estudiante de Doctorado en Antropología social con medios visuales.
} 


\title{
Velorios, santos y marimbas en el Museo Nacional de Colombia: ¿de quién es el patrimonio de la nación?
}

\section{Resumen}

En este artículo reflexionaremos acerca de dos exposiciones temporales llevadas a cabo en las instalaciones del Museo Nacional de Colombia, a partir de discusiones sobre el multiculturalismo, los procesos de patrimonialización, la nueva museología y la política de la representación. Por una parte, trataremos el caso de Velorios y santos vivos. Comunidades negras, afrocolombianas, raizales y palenqueras y, por otra, Del monumento al pensamiento. Patrimonio de Colombia para la humanidad, dos experiencias expositivas que dan cuenta de formas diferentes de concebir la nación pluriétnica y multicultural, tanto en el proceso de producción, como en el producto final presentado al público y que a su vez, evidencian los retos a los que se enfrenta esta institución estatal al buscar plasmar la lógica de la afirmación y la valorización de las diferencias introducida en la Constitución de 1991 y en la política de salvaguardia del patrimonio cultural inmaterial (PCI).

Palabras clave: Nación, Patrimonio cultural inmaterial, Museos, Afrocolombianos, Inclusión.

Palabras clave descriptores: Museo Nacional de Colombia, Multiculturalismo-Exposiciones, patrimonio cultural, Museos-Bogotá (colombia)

\section{Wakes, Saints and Marimbas in the National Museum of Colombia: Whose the Heritage of the Nation is?}

\begin{abstract}
In this article we will reflect on two temporal exhibitions held in the premises of the National Museum of Colombia, from discussions about multiculturalism, patrimonial appropriation processes, the new museology and politics of representation. First, we will consider the case of Velorios $y$ santos vivos. Comunidades negras, afrocolombianas, raizales y palenqueras and, on the other hand, Del monumento al pensamiento. Patrimonio de Colombia para la humanidad, two exhibition experiences that account for different ways of conceiving a multiethnic and multicultural nation, both in the production process and in the final product presented to the public and that in turn, show the challenges which this state institution faces when looking to capture the logic of affirmation and appreciation of difference introduced in the 1991 Constitution and in the politics of intangible cultural heritage (ICH) safeguarding .
\end{abstract}

Keywords: Nation, Intangible Cultural Heritage, Museums, Afro-colombian, Inclusion.

Key words plus: National Museum Of Colombia, Multiculturalism-Exhibitions, Cultural Heritage, Museums Bogota (Colombia)

\section{Velórios, santos e marimbas no Museu Nacional da Colômbia: ¿de quem é o patrimônio da nação?}

\section{Resumo}

Neste artigo refletimos em duas exposições temporais levadas a cabo nas instalações do Museu Nacional da Colômbia, a partir de discussões sobre multiculturalismo, os processos de patrimonialização, a nova museologia e a política da representação. De uma parte, trataremos o caso de Velórios e santos vivos. Comunidades negras, afrocolombianas, raizais e palenqueiras e, de outra, Do monumento a pensamento. Patrimônio da Colômbia para a humanidade, duas experiências expositivas que dão conta de formas diferentes de conceber a nação pluriétnica e multicultural, tanto no processo de produção quanto no produto final apresentado ao público e que, por sua vez, evidenciam os retos aos que é enfrentada esta instituição estatal ao tentar plasmar a lógica da afirmação e a avaliação das diferenças introduzida na Constituição de 1991 e na política de salvaguarda do patrimônio cultural imaterial (PCI).

Palavras-chave: Nação, Patrimônio cultural imaterial, Museus, Afrocolombianos, Inclusão.

Palavras-chave descritores: Museu Nacional da Colômbia, Multiculturalismo-exposições, Patrimônio cultural, Museus de Bogotá (Colômbia) 


\section{Introducción}

El proyecto decimonónico de nación ${ }^{5}$ imaginado por las élites andinas, requirió la construcción de un sujeto nacional homogéneo y para ello se valió, entre otras instituciones, del joven Museo Nacional de Colombia, cuyo relato negó la presencia de todos aquellos que, con su diferencia, dificultaban y erosionaban dicho ideal. La segunda mitad del siglo XX trajo consigo rupturas que llevaron a generar una conciencia -por lo menos en el discurso y en el papel- sobre la importancia de incluir y valorar a las ahora llamadas minorias étnicas, cambios que quedaron consignados en la Constitución política en 1991, la cual reconoció el carácter pluriétnico y multicultural del país, poniendo fin al discurso de la nación mestiza.

En este artículo reflexionaremos sobre dos exposiciones temporales llevadas a cabo en las instalaciones del Museo Nacional de Colombia, las cuales estuvieron enmarcadas en la lógica de la afirmación y la valorización de las diferencias introducida en la Carta de 1991 y en la politica de salvaguardia del Patrimonio cultural inmaterial (PCI). Por una parte, Velorios y santos vivos. Comunidades negras, afrocolombianas, raizales y palenqueras (2008) y por otra, Del monumento al pensamiento. Patrimonio de Colombia para la humanidad (2012-2013) dos proyectos expositivos que obedecen a distintas agendas e intereses, pero que dan cuenta de los retos que implica para una institución estatal como el Museo Nacional de Colombia, redefinir los conceptos de Nación, memoria, historia y patrimonio; pensar en las categorias étnico-raciales y en las implicaciones del uso de unas y otras, así como problematizar su relación con los sujetos étnicos y el papel que ellos cumplen en la toma de decisiones sobre qué dice el Museo ${ }^{6}$ acerca de la historia de la nación y cómo lo dice.

Para ello, la reflexión se sustenta en nuestra experiencia directa como integrantes del grupo de trabajo que produjo Velorios y santos vivos y en visitas críticas a la exposición Del monumento al pensamiento, a la luz de revisiones teóricas del multiculturalismo y a los procesos de patrimonialización, y las discusiones desde la nueva museología y la política

\footnotetext{
5 En el presente artículo utilizamos las palabras nación y estado en minúscula intencionalmente, en concordancia con nuestro intento por mostrar que son categorias construidas históricamente y situadas en contextos particulares.

6 En adelante, para hacer más fluida la lectura, cuando usamos la palabra Museo en mayúscula nos referimos al Museo Nacional de Colombia. De igual forma, en varias ocasiones usamos solo la primera parte de los títulos de las exposiciones examinadas, así: Velorios y santos vivos y Del monumento al pensamiento.
} 
de la representación, aplicadas particularmente a las relaciones entre los estados nacionales, los museos y las comunidades.

En la primera parte de este escrito, pondremos en contexto la construcción de la nación mestiza, para luego tratar desde un ángulo crítico las políticas del multiculturalismo y la patrimonialización que fueron desarrolladas a partir de la Constitución de 1991. A continuación discutiremos el caso de las dos exposiciones temporales, evidenciando aplicaciones diferentes de la idea de una nación colombiana pluriétnica y multicultural en el Museo Nacional, para concluir con algunas preguntas y reflexiones acerca de quién posee los medios para el uso y circulación de los patrimonios nacionales.

\section{El nacimiento de una nación mestiza}

Luego del proceso independentista, las élites criollas -ellas mismas heterogéneas y con proyectos de nación muy diferentes (Múnera, 2005)descontextualizaron cultural, histórica y subjetivamente todos aquellos elementos que eran identificables con el antiguo régimen, para imponerles un sentido y una significación acordes con los preceptos de desarrollo, modernidad y civilización que guiarian el futuro de la naciente Nación. Lo anterior, requirió del uso de la violencia física y simbólica, al igual que de la instrumentalización de ceremonias, símbolos e instituciones como la iglesia, la escuela y los museos, dado que para que los discursos sobre la nación puedan "retener su poder" (Özkirimli, 2005, citado por Lleras, 2011, p. 12), deben ser aprendidos e internalizados por medio de la socialización y ser reproducidos a diario.

En la marcha "hacia el progreso y la felicidad" (Múnera, 2005, p. 28), la tesis del mestizaje sirvió a las élites como panacea para civilizar a la población y fundar sobre ella una unidad nacional que fuera resumida en el lema de la Academia Colombiana de la Lengua: "una sola lengua, una sola raza, un solo Dios". Para lograrlo, era necesario llevar a cabo un proceso jerarquizado de blanqueamiento cultural y racial de las poblaciones denominadas salvajes ${ }^{7}$. Los indígenas y negros fueron entonces sometidos a la obra evangelizadora de las misiones católicas

\footnotetext{
Desde finales del siglo XVIII en Europa, pero sobre todo en el siglo XIX, la civilización se comenzó a percibir cada vez más en términos raciales de manera que características fisicas como el color de la piel, la forma de la nariz, la contextura del pelo, entre otros factores biológicos, fueron directamente asociados con inteligencia, prestigio y atributos morales. En otras palabras, las razas empezaron a construirse como entidades separadas y la civilización como un estadio del desarrollo espiritual y material al que solo podian acceder las razas más avanzadas (Múnera, 2005).
} 
para ser reducidos a la vida civilizada y territorializados en la periferia, es decir, por fuera de la región andina, no sin una gran dosis de fantasía.

En concordancia, estos territorios llamados territorios nacionales o de frontera y considerados baldíos, fueron igualmente imaginados como salvajes, lo que legitimó su conquista y sometimiento por parte de quienes se presumían civilizados -las élites criollas asentadas en las alturas de los Andes- y evidenció un ordenamiento territorial de tipo zonal a partir de una geografia racializada (Múnera, 2005) o, como lo denomina Briones (2005), unas geografias de inclusión y exclusión que supusieron la construcción de formas de representación de los indigenas y negros al margen de sus propios intereses (Cunin, 2003; Rojas y Castillo, 2005; Wade, 1997; 2002).

El museo, al igual que la escuela y la iglesia, fue una de las instituciones instauradas por las elites criollas como medio de comunicación y herramienta de educación para transmitir los principios civilizatorios, de identificación grupal, de legitimación del orden social, del imaginario de la Nación y de la jerarquía de poder (Urizar, 2008). Estas instituciones también sirvieron para organizarse y presentarse en tanto naciones modernas (Navarro, 2006) y como lugares para materializar la memoria y la historia nacional recientemente adoptada ${ }^{8}$. Por eso estas exhibieron un conjunto de objetos que se constituirian en símbolos colectivos -por lo tanto declarados patrimonio nacional (Therrien, 2011)- y cuya función sería producir una idea de madre patria.

Los museos como formas culturales con tecnologias de representación, han expresado y contribuido a generar ciertos tipos de identidad (Macdonald, 2003), convirtiéndose en sitios al servicio de la Nación, de su posicionamiento político, de sus discursos canónicos y de su imaginario (Robb, 1992, citado por Navarro, 2006). Esto explica por qué las narrativas de los museos sobre el pasado y el presente son incluyentes o excluyentes, dan voz o silencian a las colectividades y a las minorias, representan o no a los ciudadanos (Lleras, 2011).

El naciente Museo Nacional de Colombia, en concordancia con su época, se convirtió en un lugar de ostentación, en un panteón de héroes

La historiografia americana protagonizada por los europeos estuvo marcada en el siglo XVIII por el racionalismo ordenador que justificó la opresión y en el siglo XIX, por el darwinismo social. Esta historiografia pretendió olvidar a la mayoría de los actores históricos dando lugar a una crónica de las élites que negó las relaciones y puentes de intercambio entre los grupos y en algunos casos, hasta los hizo desaparecer de la historia escrita. Un ejemplo de ello es el caso de los descendientes de las castas que pasan a ser denominados en los documentos con el título genérico de mestizos luego de la abolición de las clasificaciones raciales en el siglo XIX (Guevara Sanguinés, 2005). 
y batallas y en una colección de fechas significativas -cabe preguntarse para quién- que privilegió a "los victoriosos, a las élites políticas y económicas, $\mathrm{y}$ (predominantemente) a los hombres blancos heterosexuales" (Lleras, 2011, p. 36). El Museo funcionó pues como un espacio de legitimación que, no solo construyó el patrimonio como valor, sino que le adscribió validez a diferentes cosmologías o prácticas (Lleras, 2011). Por eso, las culturas precolombinas fueron representadas solo en tanto hicieron parte de una historia lineal expresada en discursos estéticos y biológicos, mientras que los indígenas, los negros, las mujeres ${ }^{9}$, los pobres, lo cotidiano, lo popular y todo aquello que dificultaba y erosionaba la construcción de un sujeto nacional homogéneo no aparecía en el relato -o tenía una representación mínima y subordinada-. Esto llevó esto a que el Museo se constituyera en "una de las instituciones testigo de la dominación de unos pocos centros de poder sobre otros grupos" (Navarro, 2006).

De ahí todo lo que las representaciones [y narraciones] fundacionales [de la nación] tuvieron de simulacro: de representación sin realidad representada, de imágenes deformadas y espejos deformantes en los que las mayorías no podían reconocerse. (Martín-Barbero, 2000, p. 42)

\section{Una nación pluriétnica y multicultural}

Durante la segunda mitad del siglo XX el mundo vivió intensos procesos de fractura, reconfiguración y recomposición a escala local y global del espacio, de las identidades y de las relaciones de poder, que forzaron cambios drásticos en los estados. Ello generó, entre otras cosas, una conciencia -por lo menos en el discurso y en el papel- sobre la importancia de incluir y valorar a las llamadas minorias nacionales que hasta hace poco habian sido silenciadas, ignoradas y concebidas como elementos disonantes de la nación, según una visión homogénea de la misma. Se comenzó entonces a hablar desde una nueva perspectiva sobre la contribución que, en términos de diversidad, ciertos grupos habian hecho a la construcción de las naciones y se desarrollaron mecanismos jurídicos

9 Vale aclarar que no todas las mujeres ocupaban el mismo lugar. Las mujeres negras ocupaban el peldaño inferior de la sociedad, las blancas se posicionaban en la cúspide y las indígenas en el medio. 
para reconocer, defender y proteger los derechos de esos grupos ${ }^{10}$ (Boni1la, 1999; Gupta y Ferguson, 2008).

En este marco, Colombia aprobó una nueva Constitución en 1991, un hecho social e histórico que expresa las formas de concebir y representar la cultura y la diferencia cultural en contextos específicos en donde lo étnico adquiere un lugar definitorio (Restrepo, 2004). En dicha Carta, el país reconoció formalmente su carácter pluriétnico y multicultural, tomándolo "como un valor y no como un defecto" (Bonilla, 1999, p. 10) y puso fin al discurso de la nación mestiza. Ese principio y los diferentes articulados que lo desarrollan establecieron una transformación en el orden consuetudinario de la representación y de las prácticas del estado, que permitieron inaugurar una serie de espacios de participación ciudadana y crear instrumentos legales para los grupos étnicos con miras a reconocerles sus derechos colectivos ${ }^{11}$ (Restrepo, 2004; Rojas y Castillo, 2005).

Sin embargo, esta oposición esquemática entre un pasado en el que

[...] el mestizaje significaba un proceso de homogeneización caracterizado por la hegemonía del "mestizo" y un presente en el cual el multiculturalismo ${ }^{12}$ remitiría a una yuxtaposición de "grupos" con fronteras delimitadas, trasmite una visión lineal de la construcción de las naciones latinoamericanas. (Cunin, 2010, p. 13)

Así mismo, ignora que la gente ordinaria no ha sido un simple testigo silencioso del proceso histórico sino que, por el contrario, siempre ha sido agente activo del mismo (Wolf, 1987). La ruptura radical que introduce la Constitución de 1991 con la instauración de una lógica de afirmación y de valorización de la diferencia (Cunin, 2004) es producto

10 Estos derechos especiales de acuerdo con Will Kymlicka, "tienen como objetivo preservar el horizonte cultural que otorga sentido a la libertad individual y a su ejercicio, así como hacer posible la pertenencia a su grupo cultural -considerando un bien fundamental para la construcción de la identidad de muchos individuos- y promover la desaparición de las desigualdades que afectan a las minorias culturales" (Bonilla, 1999, p. 38).

11 No obstante, mientras que los indígenas fueron objeto explícito de disposiciones territoriales, económicas, educativas y politico-administrativas, las comunidades negras -como fueron denominadas en la Constitución- solo encontraron en un artículo transitorio las posibilidades de materializar sus derechos específicos, haciendo necesario el establecimiento de una comisión especial para desarrollar la Ley 70 de 1993.

12 Según Restrepo (2004) el multiculturalismo es la expresión de las formas de representación de la diferencia y la mismidad en las acciones jurídicas y políticas de los estados. La multiculturalidad, en cambio, "debe entenderse como la emergencia de la diferencia y mismidad puntuada de cultural en regímenes de verdad y de experiencia en contextos sociales y situaciones concretos, objeto de disputas y disensos" (p. 279). 
de un complejo entramado de relaciones que superponen los intereses del estado, los procesos organizativos y las movilizaciones politicas de los grupos étnicos; el renovado interés académico por el estudio de las identidades étnico-raciales, los imperativos de la politica internacional promovidas por entidades como el Banco Mundial, así como las necesidades de la globalización y la expansión del capitalismo neoliberal (Rojas y Castillo, 2005; Wade, 2004).

\section{Multiculturalismo y patrimonialización: los medios se vuelven fines}

Como una manera de apostarle al multiculturalismo, el estado ha intentado integrar a los otros ${ }^{13}$ a la Nación por medio de la promoción de sus diferencias étnicas o culturales (Chaves, 2011). Esta promoción, según Martínez-Novo (2011), ha brindado para el caso de México y Ecuador un marco de incorporación corporativa al estado que enfatiza en una sensibilidad hacia las diferencias culturales sin cuestionar la exclusión de los derechos de dichos grupos, reproduciendo así desigualdades históricas. En Colombia la situación no es muy diferente.

El reconocimiento de la diversidad cultural por parte del estado ha sido reducida a la difusión de "una imagen nacionalista, folclórica y armoniosa de un país diverso" (Salcedo, 2011, p. 287), que no se ha despojado del pensamiento decimonónico (Therrien, 2011) y que, por lo tanto, "ha permitido un reconocimiento sustantivo en rasgos, prácticas y diacríticos de una supuesta diferencia visible, que niega que la diferencia étnico-racial de los indígenas y de los afrodescendientes" está enraizada en relaciones de subordinación de vieja data, "en las que confluyen de manera compleja desigualdad social y diferencia cultural", territorializadas de acuerdo con las necesidades e intereses del poder del estado (Chaves, 2011, p. 12).

De esta forma, los sectores sociales que se autodenominan mayoritarios y dominantes, reconocen la diversidad y la particularidad étnica y cultural de otros mientras se reafirman como poseedores de una cultura universal. Así, quienes ahora son reconocidos, aunque cuentan con mayores oportunidades y posibilidades para la participación política, "serán ubicados siempre en una condición de 'minoria'

\footnotetext{
13 Los otros serian esos grupos que en otros contextos han sido llamados como minorias.
} 
en términos del reconocimiento 'real' de su ser y su saber" (Rojas y Castillo, 2005, p. 140).

Para responder a las críticas sobre el carácter contradictorio y discriminatorio de la puesta en práctica del discurso multicultural en el país -que no es otra cosa que una política para tramitar la diferencia cultural (Rojas y Castillo, 2005)-, el estado colombiano ha desarrollado una política de protección del Patrimonio cultural inmaterial (PCI) (Therrien, 2011). Dicho mecanismo, promovido por el Ministerio de Cultura con base en las directrices de Unesco, propone dar cabida a la diversidad étnica en el discurso hegemónico del patrimonio por medio de la inserción de los grupos excluidos del repertorio de bienes culturales de la Nación en las listas representativas del PCI. También, busca orientar la gestión cultural entre grupos tradicionales diferenciados hacia la revitalización y el fortalecimiento de sus identidades (Chaves, 2011).

Las críticas a este proceso han señalado que los valores y métodos utilizados para recolectar, documentar, inventariar y registrar; preservar, evaluar e interpretar experiencias vivas como los conocimientos y prácticas sustentadas en formas ancestrales de ver y aprehender el mundo, son los mismos que fueron creados décadas atrás para los patrimonios materiales (Kirshenblatt-Gimblett, 2006), bajo el supuesto retórico de que uno y otro deben ser vistos como igualmente valiosos.

Para Meza (2011), este modelo estático y esencialista del patrimonio inmaterial, fácilmente lo reduce a expresiones muertas y embalsamadas, propensas a su disección y clasificación taxonómica en saberes, destrezas, recetas y cosmovisiones ajenas a la experiencia vivida de los grupos humanos para los que dichas prácticas culturales tienen sentido. De igual manera, ignora que las tradiciones son una construcción histórica íntimamente relacionada con universos estéticos y simbólicos, así como con sistemas socioeconómicos y medioambientales que actúan de manera integral en la comprensión y generación de respuestas frente a los procesos de cambio, por lo que pueden desaparecer, ser reinventadas o puestas en escena en contextos radicalmente diferentes (Chaves, Montenegro y Zambrano, 2010; Hobsbawm y Ranger, 2002; Meza, 2011).

La construcción del patrimonio es una práctica cultural que se vale del paradójico "efecto museo"14 (Alpers, 1991, citado por Kratz,

14 El "efecto museo" es el proceso por el cual los museos extraen y reubican objetos y prácticas de la cotidianidad en nuevos contextos, y de tal forma generan y validan maneras particulares de ver y de prestar atención (Alpers, 1991, citado por Kratz, 2002). 
2002), en el cual, lo cotidiano se vuelve espectacular (KirshenblattGimblett, 1998) y se re-categoriza como bien cultural susceptible de hacer parte de las listas del PCI (Chaves et al., 2010), controladas desde el lugar y los discursos dominantes, sometidas a sus formas y tramitadas en su espacio (Rojas y Castillo, 2005). Aunque la politica del PCI se propone como un proceso incluyente y participativo, las decisiones sobre qué se patrimonializa, cómo se distribuyen los beneficios que este patrimonio produce y quiénes tienen derecho al uso, la propiedad, la circulación y la distribución de los bienes y saberes patrimonializados, no son inmunes a las desigualdades que producen las jerarquías y el direccionamiento del centro a la periferia (Chaves, 2011; Chaves et al., 2010).

\section{¿Un museo del siglo XIX se vuelve multicultural?}

Con todo lo anterior como telón de fondo, el Museo Nacional de Colombia se encontró ante un amplio desafio: enfrentarse a la definición de una nueva forma de entender la sociedad, pensar cómo materializar los cambios acarreados por el multiculturalismo, redefinir los conceptos de Nación, memoria, historia y patrimonio nacional y las formas de narrar el pasado y el presente; reevaluar la relación que tiene con el público y con los ciudadanos, así como la participación de los diferentes sectores de la sociedad y de las regiones del país en la toma de decisiones sobre sus contenidos (Lleras, 2011; Urizar, 2008).

Como respuesta a este reto y en concordancia con el Plan estratégico 2001-2010. Bases para el Museo Nacional del futuro, la Curaduría de Arte e Historia del Museo lideró un proyecto que buscaba nutrir las colecciones con nuevas formas de patrimonio, ampliar las nociones de ciudadanía y del papel de los ciudadanos en la institución, de forma que reflejaran los planteamientos de la Carta de 1991. Esta necesidad surgió a partir de la detección de vacíos en las colecciones relacionados con fenómenos sociales, económicos y culturales de la segunda mitad del siglo XX, pero también, con el reconocimiento de que la narrativa del Museo había sido hecha a partir de la exclusión de historias, personajes y perspectivas fundamentales en el devenir de la Nación (Lleras, 2011).

A continuación analizaremos dos actividades expositivas llevadas a cabo en las instalaciones del Museo que dan cuenta de la complejidad y dificultades que comporta la intención de reflejar la nueva idea 
de nación colombiana pluriétnica y multicultural, en una institución creada como parte de un proyecto de nación del siglo XIX.

\section{Exposición temporal Velorios y Santos Vivos. Comunidades negras, afrocolombianas, raizales y palenqueras}

Las reflexiones que presentamos en la siguiente sección se basan, por una parte, en nuestra vinculación como miembros del equipo de trabajo encargado de la investigación y producción de Velorios y santos vivos, así como con actividades y proyectos derivados de esta muestra. Por otra parte, nos remitimos al estudio de públicos de la exposición y a la tesis doctoral realizada por Cristina Lleras (2011), entonces curadora jefe de la Curaduría de Arte e Historia del Museo Nacional de Colombia.

Según relata Lleras (2011), luego de algunos intentos iniciales en la década de 1990 por reflexionar, investigar o transformar la participación de los afrodescendientes en las narrativas del Museo Nacional de Colombia, algunos académicos volvieron a disparar las alarmas en el 2005 sobre la inadecuada representación de los grupos negros en el museo de la Nación. A partir de entonces, miembros de las comunidades afrocolombianas, historiadores, antropólogos y funcionarios del Museo comenzaron un proceso de discusión sobre el tema y decidieron realizar una exposición temporal, la primera en su género en el Museo Nacional de Colombia, que buscaba subsanar -con la conciencia de que esta no era una solución definitiva- la ausencia y tergiversación en las representaciones de los afrodescendientes, en el marco de las reparaciones establecidas por la Conferencia de Durban $2001^{15}$.

El grupo de trabajo consideró diferentes temas para la exposición y optó por exaltar la riqueza estética, simbólica y espiritual contenida en los rituales fúnebres, la relación con los ancestros y la devoción a los santos católicos como renovadores de los lazos de solidaridad de las comunidades de ascendencia africana en Colombia. Escogieron este tema porque involucraba a todos los grupos de ascendencia africana en el país y servía como medio para manifestar "la inconformidad de muchas comunidades por la manera como los grupos armados de todas las tendencias y afiliaciones -de manera

\footnotetext{
Del 31 de agosto al 8 de septiembre de 2001 se celebró en Durban, Sudáfrica, la Tercera Conferencia Mundial contra el Racismo, la Discriminación Racial, la Xenofobia y las Formas Conexas de Intolerancia. En virtud de la Declaración y el Programa de Acción de Durban, los estados se comprometieron a luchar contra esas formas de racismo y reconocieron que la esclavitud y la trata de esclavos eran delitos de lesa humanidad y fomentaban el racismo. Para mayor información sobre la Conferencia véase: http://www.un.org/spanish/CMCR/
} 
sistemática- han impedido que la gente lleve a cabo las ceremonias alrededor de la muerte, incluyendo el entierro propiamente dicho" (Arocha, Botero, Camargo, González y Lleras, 2008, p. 21).

En 2007 se conformó un seminario permanente compuesto por cinco profesionales afrocolombianos provenientes de varias regiones del país y residentes en Bogotá, antropólogos y funcionarios del Museo para discutir periódicamente sobre la metodología de investigación ${ }^{16}$, los contenidos, la curaduría y museografia de la exhibición. El proceso se caracterizó por el diálogo, los desacuerdos y descubrimientos. Desde un comienzo, los afrocolombianos participantes en el seminario dejaron claro que cualquier decisión respecto a qué mostrar y cómo y qué excluir de la exposición debía consultarse con ellos: su voz debía ser escuchada a lo largo del proceso y ser visible en su resultado (Lleras, 2011).

Fue así como la exposición temporal Velorios y santos vivos. Comunidades negras, afrocolombianas, raizales y palenqueras ${ }^{17} \mathrm{se}$ abrió al público entre el 21 de agosto y el 2 de noviembre 2008 en la sala de exhibiciones temporales del Museo Nacional. Los elementos centrales de esta muestra fueron tres altares a santos patronos: San Pacho en Quibdó (Chocó), la Virgen del Carmen en Tumaco (Nariño) y el pesebre de las adoraciones del norte del Cauca, así como cuatro espacios que buscaban reproducir el lugar de la casa donde tiene lugar el velorio de acuerdo con las diferentes tradiciones locales: una habitación vestida de blanco en las islas San Andrés, Providencia y Santa Catalina, un altar de angelito en Uré (Córdoba), un altar de novena y otro de última noche en San Basilio de Palenque (Bolivar) y un altar de última noche en Guapi (Cauca). Cada uno de estos espacios fue diseñado y construido por una o varias personas de las regiones representadas en la muestra, que viajaron a Bogotá para ello. De igual manera, la exposición vinculó a varios jóvenes afrocolombianos como monitores guías y fue acompañada de un programa semanal de actividades a cargo

16 La investigación fue liderada por el antropólogo Jaime Arocha en compañía con varios otros antropólogos miembros del Grupo de Estudios Afrocolombianos, enmarcados en la tradición investigativa de Nina S. de Friedemann. Esto hizo que el método utilizado fuera el etnográfico. El trabajo de campo para reunir información, fotografias y videos para la exposición fue llevado a cabo en periodos cortos entre mayo de 2007 y abril de 2008 en el archipiélago de San Andrés, Providencia y Santa Catalina, Chocó, la zona plana del norte del Cauca, Guapi y Limones del mismo departamento, Tumaco y el río Mira en Nariño, San Basilio de Palenque en Bolivar y San José de Uré en Córdoba. En cada lugar visitado se contó con la participación de un profesional afrocolombiano oriundo de la región y al menos un antropólogo.

17 Para mayor información sobre la exposición temporal véase: http://www.museonacional.gov. co/sites/velorios/veloriospre.html 
de personas de las regiones representadas, el cual sirvió para conversar con el público sobre los temas expuestos.

Todas estas acciones, pensadas como mecanismos de participación o autorepresentación y por lo tanto de inclusión, moldearon el desarrollo del proyecto. Sin embargo, cabe preguntarse si hubo transformaciones profundas respecto a quién representa a quién, o quién toma las decisiones sobre qué mostrar o no en el Museo. Como fue evidente durante todo el proceso de investigación y curaduría, así como en los grupos focales y las entrevistas realizadas por Lleras (2011), la iniciativa de Velorios y santos vivos generó múltiples reacciones antes y después del montaje de la exhibición temporal. Quienes estaban de acuerdo con el proyecto lo veían como un mecanismo de exaltación de la cultura afrocolombiana, como un medio para legitimar su historia $\mathrm{y}$ visibilizar los aportes que estas comunidades han realizado a la formación de la Nación. Para algunos visitantes la exposición semejaba un espejo, un lugar donde propios y extraños pudieron verse reflejados y una herramienta para la memoria. Hubo incluso quienes, con base en sus contenidos, tendieron a idealizar las tradiciones, prácticas y grupos representados en la exposición ${ }^{18}$.

Entre quienes criticaron la exposición, algunos opinaron que reforzaba los estereotipos sobre la gente negra y la exotizaba, mientras otros expresaron su desacuerdo con hacer parte de una institución que, para ellos, representa el status quo y la hegemonía de las élites colombianas. Hubo quienes desaprobaron que su primera aparición en el Museo estuviera relacionada con la muerte y otros, manifestaron que las espiritualidades de los afrocolombianos, negros, raizales y palenqueros con sus altares a los difuntos y a los santos son sagrados y por ello, no debian ser descontextualizados y puestos en escena en un museo.

Tal descontento merece atención si consideramos que de acuerdo con Kirshenblatt-Gimblett (1998), una de las caracteristicas definitorias de las producciones patrimoniales es que los lugares donde se muestran, tales como festivales y exposiciones de museos, son extraños a su tradición. Estos nuevos contextos o interfaces son en sí mismos formas culturales y máquinas poderosas de significados, así como productores de "mensajes de reconciliación, multiculturalismo o biculturalismo, o de desarrollo" (Kirshenblatt-Gimblett, 1998, p. 157).

18 Esta reacción fue problematizada en la tesis de Lleras (2011), en el sentido de que tal idealización puede ser, aunque positiva, estereotipada y esencialista. 
A su vez, hubo cuestionamientos sobre la composición del equipo curatorial. Los grupos focales que realizó Lleras (2011) con personas pertenecientes a las comunidades negras, raizales, palenqueras y afrocolombianas, dejaron ver que algunos de ellos y ellas pusieron en duda la representatividad de los miembros de los grupos que participaron en el proceso e incluso, expresaron su descontento con respecto a la participación de funcionarios y profesionales blancos o mestizos en esta muestra pionera en el Museo Nacional. Lo anterior confirmaría que, pese a los supuestos cambios generados con el multiculturalismo, los grupos étnicos aún carecen del poder y los medios para representarse a sí mismos y requieren de la intermediación de agentes externos para interactuar con instancias públicas (Lleras, 2011).

El estudio de públicos de Velorios y santos vivos dejó ver que ninguna de las formas de inclusión llevadas a cabo en su desarrollo fue vista como suficiente para dar cuenta del aporte afro o negro a la Nación colombiana (Lleras, 2011). Tanto el proceso de investigación y montaje como las reacciones frente a la exposición temporal, mostraron cuán heterogéneas son las visiones acerca de la identidad, la autoridad y la representación, así como lo complejo de la idea misma de intentar hablar acerca de los afrocolombianos, negros, raizales y palenqueros simultáneamente ${ }^{19} \mathrm{y}$ de incluir a quienes han sido excluidos como tema y como voz del relato de nación que el Museo narra en sus paredes, vitrinas y corredores.

En este contexto se dio inicio a la itinerancia de la exposición, planteada desde el proyecto original como un mecanismo para devolver los resultados de la investigación a los participantes de la misma ${ }^{20}$. A partir de 2009 y por cuatro años consecutivos, la muestra viajó por todo el país $^{21}$ en respuesta a las peticiones que formularon organizaciones afro, instituciones educativas y casas de la cultura, entre otras instancias. El diseño de la exposición fue particular en cada caso, correspondió a las tradiciones locales y a los intereses de los organizadores y responsables, por eso, si en algunas muestras construyeron altares fúnebres,

19 La exposición se adscribió a la noción oficial de comunidades negras, afrocolombianas, raizales y palenqueras, pero buscó ampliarla en la pared exterior de la sala de exposiciones temporales con denominaciones de uso local como niches, libres, renacientes, morenos, entre otros, respetando el hecho de que algunas personas defienden la afiliación étnica y, por eso, se autodenominan como afrocolombianos, mientras otras defienden la idea de raza para referirse a sí mismas (Lleras, 2011).

20 Para mayor información sobre la exposición itinerante véase: http://museonacional.gov.co/ sites/Velorios_site/Index.html

21 El tercer y cuarto año de itinerancia estuvo a cargo de una joven afrocolombiana que participó de la versión temporal como monitora guía. Los primeros sitios visitados fueron los lugares donde se llevó a cabo el trabajo de campo, luego continuó viajando por todo el país. 
en otras, los encargados no lo consideraron apropiado porque, como lo manifestaron en San Basilio de Palenque y en Guapi, armar un altar fúnebre sin difunto traería ruina o llamaría muerto, mientras que en ciudades como Buenaventura, Padilla o Medellín, el altar fue dedicado a una persona destacada de la comunidad, fallecida con anterioridad.

Durante el recorrido de esta exposición, la recepción y apropiación por parte de los asistentes también varió de lugar a lugar, insertándose en mayor o menor medida en sistemas locales de visibilización y reconocimiento de la gente negra, afrocolombiana, raizal y palenquera y en sistemas burocráticos e institucionales de gestión de la multiculturalidad en las regiones. En algunos casos, ella se convirtió en un escenario o en motivador para la realización de rituales casi olvidados. En otros, fue una herramienta para interactuar o crear alianzas con instancias oficiales y no oficiales a nivel regional y nacional, o simplemente pasó desapercibida para los habitantes locales.

\section{Exposición temporal Del monumento al pensamiento. Patrimonio de Colombia para la humanidad}

A diferencia de la sección anterior donde la experiencia directa en el proceso de investigación y producción de la exposición sustentó nuestras reflexiones, basaremos el subsiguiente análisis en nuestra experiencia como visitantes a Del monumento al pensamiento. Patrimonio de Colombia para la humanidad, en el estudio de públicos de la exhibición que contrató el Museo Nacional, en una entrevista a su curador, el antropólogo Germán Ferro, realizada por una de las autoras de este artículo y en algunos documentos públicos relacionados con la declaratoria patrimonial de las Músicas de marimba y cantos tradicionales del Pacífico sur de Colombia.

Con motivo de la celebración del cuadragésimo aniversario de la Convención sobre la Protección del Patrimonio Mundial Cultural y Natural de 1972 y del décimo aniversario de la Convención para la Salvaguardia del Patrimonio Cultural Inmaterial de 2003, la Dirección de Patrimonio del Ministerio de Cultura contrató a la Fundación Erigaie ${ }^{22}$ para realizar una exposición temporal cuyo objetivo fundamental era

22 El equipo de la Fundación Erigaie también realizó la curaduría de la exposición temporal Río Magdalena. Navegando por una Nación (28 de febrero al 4 de mayo de 2008) en el Museo Nacional y organizó la muestra que Colombia presentó en julio de 2011 en el Smithsonian Folklife Festival en Washington D.C. como país invitado de honor. Para mayor información sobre la Fundación Erigaie, véase: http://www.erigaie.org/ 
que los ciudadanos colombianos conocieran su patrimonio cultural y lo valoraran "como una de sus mayores riquezas" (Ministerio de Cultura, 2010, p. 236).

Así, la exposición temporal Del Monumento al pensamiento ${ }^{23}$ abrió sus puertas al público en las instalaciones del Museo del 25 de octubre de 2012 al 20 de enero de 2013. Consistió en "una invitación a comprender y reconocer el significado cultural" (Museo Nacional de Colombia, 2012) de los siete lugare ${ }^{24}$ y las siete manifestaciones ${ }^{25}$ colombianas inscritas hasta ese momento ${ }^{26}$ en las listas de Patrimonio Mundial y Patrimonio de la Humanidad de Unesco. También fue un llamado "a explorar sus aportes a nuestra constitución como pueblo y nación" (Museo Nacional de Colombia, 2012) puesto que, en conjunto:

[...] forman una herencia histórica que incita a una reflexión sobre nuestro presente, y motivan nuevas maneras de percibir, sentir y comunicarnos con las comunidades portadoras de este patrimonio y con el legado moral que este entrega a la humanidad. (Museo Nacional de Colombia, 2012)

La exposición fue planteada como un recorrido del monumento al pensamiento -tal como lo señala su título- organizado en cinco ejes temáticos: herencia hispánica, huella precolombina, ecosistemas culturales y biodiversidad, mestizaje cultural festivo, palabra y pensamiento ancestral. Cada sitio o manifestación fue condensado en una especie de estación donde se expusieron textiles, instrumentos musicales, mobiliario, obras de arte, material audiovisual, textos; recreaciones como

${ }^{23}$ Para mayor información sobre la exposición temporal véase: http://www.museonacional.gov. $\mathrm{co} /$ sitio/patrimonio/default.aspx

24 De los 962 sitios que hacen parte de la lista de Patrimonio Mundial, siete de ellos se encuentran en Colombia: Puerto, fortificaciones y conjunto monumental de Cartagena (1984), Parque Nacional Natural Los Katíos (1994), Centro Histórico de Santa Cruz de Mompox (1995), Parque Arqueológico de San Agustín (1995), Parque Arqueológico de Tierradentro (1995), Santuario de Fauna y Flora de Malpelo (2006) y Paisaje Cultural Cafetero (2011).

25 Siete de las 232 manifestaciones registradas en la lista de Patrimonio Cultural Inmaterial son colombianas: Carnaval de Barranquilla (declarado obra maestra del patrimonio oral e inmaterial de la humanidad en 2003 e inscrito en la Lista en 2008), Espacio cultural de Palenque de San Basilio (tuvo igual declaratoria en 2005 y fue inscrito en la Lista en 2008), Carnaval de Negros y Blancos de Pasto (2009), Procesiones de Semana Santa de Popayán (2009), Sistema normativo Wayúu aplicado por el Putchipu’ui (palabrero) (2010), Músicas de marimba y cantos tradicionales del Pacífico sur de Colombia (2010) y Los conocimientos tradicionales de los chamanes Jaguares de Yurupari (2011).

26 En diciembre de 2012, Unesco inscribió en la lista de Patrimonio Inmaterial de la Humanidad la Fiesta de San Pacho, celebrada en homenaje a San Francisco de Asís, santo patrono de la ciudad de Quibdó (Chocó), completando así 15 sitios y expresiones colombianas. 
el hipogeo de Tierradentro con sus pinturas murales, reproducciones de construcciones tradicionales como la ranchería wayúu, la maloka amazónica o la empalizada palenquera, al igual que materiales originales como la irónica carroza "Don Patrimonio" que mostraba las implicaciones ambiguas de las declaratorias patrimoniales y que fue fabricada especialmente para la sección del Carnaval de Negros y Blancos de la exposición.

Nuestra familiaridad con el tema de los velorios entre la gente del Pacífico hizo inevitable notar con desconcierto que la curaduria de Del monumento al pensamiento agrupara a las Músicas de marimba y cantos tradicionales del Pacífico sur de Colombia con los Carnavales de Barranquilla y de Negros y Blancos de Pasto en el eje temático Mestizaje cultural festivo por compartir "esa alegria festiva que recorre amplias regiones de Colombia” (Museo Nacional de Colombia, 2012).

Tal desconcierto se basa por una parte, en que esa decisión curatorial señala una desatención al artículo 7 de la Constitución de 1991 que identifica a Colombia como un país multiétnico y pluricultural y por otra, en que todos los documentos públicos acerca de las Músicas de marimba y cantos tradicionales del Pacífico sur los reconocen como patrimonio cultural de los afrocolombianos y afrodescendientes de los departamentos del Valle del Cauca, Cauca y Nariño, donde constituyen $90 \%$ de la población y que, según el Expediente de candidatura, "comparten la condición de descender de contingentes de esclavos que fueron brutalmente importados al Virreinato de la Nueva Granada, hoy Colombia, desde el siglo XVIII" (Unesco, 2010, p. 2). Estos cantos y músicas fueron incluidos en la lista del Patrimonio Cultural Inmaterial en noviembre de 2010 y declarados como tal con base en procesos de consulta con líderes y miembros de consejos comunitarios de los tres departamentos.

El expediente (Unesco, 2010) también afirma que las Músicas de marimba y cantos tradicionales del Pacífico sur combinan las canciones de mujeres y hombres con el sonido de instrumentos acústicos fabricados localmente. Las interpretaciones musicales se dan durante la celebración de uno de estos cuatro ritos: el arrullo, el currulao, el chigualo y el alabao. El arrullo es un rito en honor a los santos católicos que fue ilustrado en la exposición con un altar a San Pacho. El currulao o baile marimbas, es un evento festivo en el que los hombres tocan estos instrumentos e interpretan cantos profanos acompañados de tambores y guasás, mientras los participantes cantan, bailan, comen, beben y narran relatos; evento que fue ilustrado con una pintura de Guillermo 
Wiedemann así como con varios tambores y una marimba fabricados por don Baudilio Cuama, un hombre mestizo de la región de Buenaventura que hace marimbas como estrategia para enfrentarse a la realidad de la guerra que vive el país (Ferro, 2013).

El chigualo, de otra parte, es la ceremonia fúnebre realizada a niños y niñas menores de siete años que incluye bailes, juegos y cantos ante el cuerpo del difunto cubierto de flores, escena que fue representada en la exposición con la presencia de un ataúd pequeño de color blanco. El alabao es el velorio de un adulto en el que se entonan cantos a cappella que trasmiten muchos sentimientos. Por lo general, amigos y familiares del difunto se reúnen en la parte exterior de la casa para jugar, contar chistes e historias, beber y fumar; espacio que fue posible apreciar en la exhibición gracias a una mesa en la que se podía jugar parqués ${ }^{27}$. Adicionalmente, el expediente señala que este patrimonio musical de los afrocolombianos y los conocimientos asociados, se transmiten oralmente de generación en generación y de los pueblos de origen a las zonas urbanas, donde siguen siendo fuente de identidad comunitaria.

Aludiendo a la autonomía curatorial -la opción de valerse de interpretaciones y posiciones personales como recurso para ordenar los contenidos de una exhibición- y enfatizando que su posición se cimienta en años de experiencia etnográfica en la región, el curador de la exposición temporal defendió el uso de las categorías de mestizo y mestizaje en términos culturales, pues consideraba que, aunque la marimba es un instrumento de tradición afro, ha sido enriquecida y compartida por varios grupos ${ }^{28}$ y es justamente en los procesos de sobrevivencia, transformación, resignificación y reafirmación en nuevos escenarios que yace su riqueza y su carácter mestizo.

Aunque la autonomía curatorial puede ser un criterio válido para tomar decisiones con respecto a qué mostrar y decir en una exposición, nombrar o dejar de hacerlo es un acto de poder (Olson, 1998). ¿Qué implicaciones tiene entonces utilizar nombres y categorias diferentes a los usados durante el proceso de consulta y validación que

\footnotetext{
27 Tanto el tablero de parqués -con sus dados y fichas-como los instrumentos musicales podian ser manipulados por los visitantes, rompiendo así, la tradicional barrera de los museos de no tocar. De acuerdo con el estudio de públicos de la exposición, esta idea y la sensación de encontrarse viajando por el territorio nacional a medida que se recorria la exhibición, fueron muy bien recibidas por los visitantes, en su mayoria colombianos y nacidos en Bogotá (Lozano y Quiroga, 2012).

28 Según el expediente de candidatura, aunque los afrocolombianos son los portadores principales de esta manifestación, también es practicada por mestizos e indígenas del departamento de Nariño (Unesco, 2010).
} 
dio lugar a la declaratoria y que designa a los afrocolombianos y afrodescendientes del Pacífico sur colombiano como poseedores de este patrimonio cultural particular? ¿Quién cuenta con las herramientas para tomar una decisión de este tipo? Lo que está aquí en juego es el uso, la circulación y el usufructo de este patrimonio y es responsabilidad del Ministerio de Cultura, de su Dirección de Patrimonio y del Museo Nacional, garantizar que sean los grupos que detentan un patrimonio quienes decidan cómo proceder, para así evitar que por medio del proceso de patrimonialización, se "detenga o embargue lo que se muestra" (Kirshenblatt-Gimblett, 1998, p. 159).

Reconocemos que las categorias étnicas y raciales pueden ser problemáticas, en parte porque se han convertido en herramientas para un tipo de inclusión que es meramente nominal, pero no hacer alusión a ellas es una manera de desconocer a las poblaciones negras, afrocolombianas raizales y palenqueras, regresando al pensamiento decimonónico del ciudadano universal y de la nación mestiza ${ }^{29}$. A continuación discutiremos las posibles consecuencias de un retroceso tal y señalaremos posibles alternativas.

\section{El patrimonio marca Unesco ${ }^{30}$ exhibido en el Museo Nacional}

Los museos reflejan, invocan y producen la realidad (Lleras, 2011; Macdonald, 2003). Sus exposiciones funcionan como formas culturales de representación y de comunicación a múltiples niveles (Kratz, 2002) y de esta forma, constituyen lo que exhiben -con mayor o menor éxito- en arte, patrimonio o cultura (Kirshenblatt-Gimblett, 1998). Pero si bien estas prácticas de carácter hegemónico han legitimado tradicionalmente jerarquías y estereotipos, también pueden servir para contar historias de resurgimiento, rememoración y lucha (Clifford, 1997).

29 Luego de la abolición legal de la esclavitud en 1851, los descendientes de africanos existían como grupo pero no tenian un estatus administrativo diferente al de cualquier otra comunidad campesina. La categoria de negro/a era reconocida socialmente, sus miembros sufrian de discriminación por su causa y sin embargo, no tenian la calidad de otro que tenían los indigenas. Ellos eran vistos como ciudadanos universales de acuerdo con el modelo republicano francés, por eso los términos de raza, etnia o color fueron suprimidos del lenguaje administrativo, mientras que las personas debieron ser integradas a la nación en el marco del mestizaje (Cunin, 2003; Rojas y Castillo, 2005; Wade, 1997; 2002).

30 Isaza (2012), director de la División de Patrimonio del Ministerio de Cultura, afirmó que "ser patrimonio mundial es una marca muy codiciada, un sello de calidad. Estos bienes representan todo esto y un esfuerzo de la comunidad internacional por lo más granado, lo más selecto, lo más valioso de ese transcurrir de la humanidad por este planeta". 
Es fácil criticar diciendo que cualquier representación de un grupo subalterno por parte del estado es sólo simbólica o que no representa adecuadamente al grupo en cuestión. Pero es importante reconocer los elementos potencialmente transformadores de esos procesos. Aunque Velorios y santos vivos fue percibida como una iniciativa insuficiente y en muchos casos problemática, abrió las puertas para hacer las cosas de otra manera, señaló posibles caminos para transformaciones más profundas y puso sobre la mesa la complejidad de incorporar a quienes han sido excluidos de la idea de nación representada en las salas del Museo. Que tenga lugar una exposición acerca de los afrocolombianos, negros, raizales y palenqueros en el Museo Nacional fácilmente se puede reducir a un mecanismo de inclusión nominal. Que se abran espacios para que personas adscritas a estas categorias hagan exposiciones sobre sí mismas, trasciende el cumplimiento de un requisito burocrático y da pie a que sean ellas quienes decidan y definan cómo quieren aparecer, nombrarse e incluso, si quieren o no hacerlo.

La exposición Del monumento al pensamiento tomó otro camino. En ella primó esa idea de la patrimonialización que le arrebata las tradiciones culturales a sus dueños (Kirshenblatt-Gimblett, 1998), para tramitarlas según conveniencia del estado o del mercado. Al exhibir las manifestaciones portadoras de la marca Unesco en el Museo Nacional, el Ministerio de Cultura y su Dirección de Patrimonio las validan como patrimonio de la humanidad y como patrimonio de la Nación colombiana, legitimando un modelo de patrimonialización que proviene de Unesco. Cabe entonces preguntarse dónde quedó la razón inicial por la que las Músicas de marimba y cantos tradicionales del Pacífico sur de Colombia merecian ser protegidos: su valor como herramienta para la visibilización, la resistencia y la supervivencia de un grupo humano (Unesco, 2010).

Desafortunadamente, en Colombia el lenguaje de la inclusión y la diversidad no tiene repercusiones en la calidad de vida de las comunidades, puesto que no se ha entendido que el reconocimiento de los aportes a la construcción de la nación, así como de las particularidades de la gente negra y afrocolombiana -como de tantos otros excluidos- no es un fin en sí, sino una herramienta para tratar otras inequidades, como el despojo territorial y la negación de los derechos fundamentales (Arocha, 2006; Lleras, 2011).

Los cuestionamientos sobre quiénes conformaron los equipos curatoriales y el tipo de decisiones que ellos tomaron dejan abierta la pregunta sobre cómo hacer para que los grupos étnicos cuenten con 
el poder y los medios para representarse a sí mismos sin la intermediación de agentes externos para interactuar con instancias públicas.

El reto actual para los museos -así como para otras instituciones encargadas de proteger, investigar, comunicar, usar y circular el patrimonio- está en cambiar tanto las narrativas y las formas de representación, como su funcionamiento interno (Lleras, 2011) y para ello, podrian valerse de figuras como la confianza radical propuesta por Lynch y Alberti (2010) y la zona de contacto acuñada por Pratt a comienzos de la década de 1990 y posteriormente aplicada a la museología por Clifford en 1997 (Boast, 2011). En un proyecto basado en la confianza radical, "el museo no controla el resultado final" (Lynch y Alberti, 2010, p. 19), por el contrario, desarrolla una serie de relaciones y habilidades que incluyen el disenso como medio para la generación de conversaciones y admite los conflictos e incluso el fracaso como parte necesaria en los procesos de incorporación de voces antes silenciadas en las narrativas de los museos.

Un compromiso de este estilo iría más allá "de la retórica de la asociación y de las prácticas de consulta superficiales" (Lynch y Alberti, 2010, p. 20), para ubicarse en una zona de contacto, donde tienen lugar procesos auténticos de colaboración y coproducción, de intercambio de saberes, así como de traducción y transculturación, en los cuales los colonizados, pueden producir auto-etnografias o expresiones autoetnográficas (Boast, 2011).

El Museo Nacional se encuentra actualmente en un proceso de renovación de los guiones de sus salas permanentes. Según afirmó recientemente su directora María Victoria de Robayo en una entrevista:

[...] el museo está absolutamente comprometido con una transformación de los guiones, de tal manera que cuente la historia del país vista desde distintas perspectivas, no solo desde la historia de los gobernantes, del liderazgo, sino de quienes han hecho esta $\mathrm{Na}$ ción, que somos todos los colombianos: los trabajadores, los campesinos, etc. Hay que agrandar el museo, no sólo en términos de espacio, sino de concepción de país. (El Espectador, 2013)

¿Cómo se enfrentará el Museo Nacional de Colombia a los retos que plantea la intención de narrar la historia del país desde múltiples lugares de enunciación? ¿Existen las condiciones y la voluntad institucionales para que en su equipo de trabajo se incluyan a los diferentes grupos poblacionales? ¿Caerá en la trampa de la museificación 
decimonónica de la historia y de la disney-ificación del patrimonio cultural inmaterial? $\mathrm{O}$ ¿Continuará siendo un lugar de legitimación de una visión de Nación que se realiza desde el poder? Para evitarlo, es necesario que revise y construya sobre su propia historia.

\section{Referencias}

Arocha, J. (2006). Afro-Colombia en los años post-Durban. Palimpsesto, 5, 26-41.

Arocha, J., Botero, J., Camargo, A., González, S. y Lleras, C. (2008). Velorios y santos vivos. Comunidades negras, afrocolombianas, raizales y palenqueras. Bogotá: Museo Nacional de Colombia.

Bonilla, D. (1999). La ciudadanía multicultural y la politica del reconocimiento. Bogotá: Universidad de los Andes.

Boast, R. (2011). Neocolonial Collaboration: Museum as Contact Zone Revisited. Museum Anthropology, 34 (1), 56-70.

Briones, C. (2005). Formación de alteridad: contextos globales, procesos nacionales y provinciales. En C. Briones (Ed.). Cartografias argentinas: politicas indigenistas y formaciones provinciales de identidad (pp. 11-43). Buenos Aires: Antropofagia.

Chaves, M. (2011). Presentación. En M. Chaves (Comp.). La multiculturalidad estatalizada. Indigenas, afrodescendientes y configuraciones del Estado (pp. 9-24). Bogotá: ICANH.

Chaves, M., Montenegro, M. y Zambrano, M. (2010). Mercado, consumo y patrimonialización cultural. Revista Colombiana de Antropología, 46 (1), 7-26.

Clifford, J. (1997). Routes. Travel and Translation in the Late Twentieth Century. Cambridge: Harvard University Press.

Cunin, E. (2003). Identidades a flor de piel. Lo 'negro' entre apariencias y pertenencias: mestizaje y categorias raciales en Cartagena (Colombia). Bogotá: IFEA, ICANH, Universidad de los Andes y Observatorio del Caribe Colombiano.

Cunin, E. (2004). De la esclavitud al multiculturalismo: el antropólogo entre identidad rechazada e identidad instrumentalizada. En E. Restrepo y A. Rojas (Eds.). Conflicto e (in)visibilidad. Retos en los estudios de la gente negra en Colombia (pp. 141-156). Popayán: Universidad del Cauca.

Cunin, E. (2010). Introducción. En E. Cunin (Coord.), Mestizaje, diferencia y Nación. Lo "negro" en América Latina y el Caribe (pp. 13-32). México: INAH, UNAM e IRD.

El Espectador. (2013, 9 de julio). "No hay que aspirar a verlo todo". Recuperado el 9 de julio de 2012, de http://www.elespectador.com/entretenimiento/ unchatcon/articulo-432452-no-hay-aspirar-verlo-todo 
Ferro, G. (2013, 28 de junio). Entrevista, Bogotá.

Guevara Sanguinés, M. (2005). Perspectivas metodológicas en los estudios historiográficos sobre negros en México hacia finales del siglo XX. En M. E. Velázquez y E. Correa (Comps.). Poblaciones y culturas de origen africano en México (pp. 65-82). México: INAH.

Gupta, A. y Ferguson J. (2008). Más allá de la "cultura": espacio, identidad y las políticas de la diferencia. Antipoda, 7, 233-256

Kirshenblatt-Gimblett, B. (1998). Destination Culture: Tourism, Museums, and Heritage. Berkeley, Los Angeles: University of California Press.

Kirshenblatt-Gimblett, B. (2006). World Heritage as Cultural Economics. En I. Karp, et al. Museum Frictions. Public Culture/Global Transformations (pp. 161202). Durham: Duke University Press.

Hobsbawm, E. y Ranger, T. (Eds.). (2002). La invención de la tradición. Barcelona: Critica.

Isaza, J. L. (2012, 20 de noviembre). Colombia y el patrimonio mundial. Conferencia presentada en el marco de la exposición temporal Del monumento al pensamiento. Patrimonio de Colombia para la humanidad, Bogotá.

Kratz, C. A. (2002). The Ones that are Wanted. Communication and the Politics of Representation in a Photographic Exhibition. Berkeley, London: University of California Press.

Lleras, C. (2011). Towards New Narratives of the Multicultural Nation: Negotiating Difference in the National Museum of Colombia. Tesis de doctorado no publicada, University of Leicester, Reino Unido.

Lozano, Z. y Quiroga Á. M. (2012). Estudio de público exposición temporal Del monumento al pensamiento. Patrimonio de Colombia para la humanidad. Bogotá: Museo Nacional de Colombia, inédito.

Lynch, B. T. y Alberti, S. (2010). Legacies of Prejudice: Racism, Co-production and Radical Trust in the Museum. Museum Management and Curatorship, 25 (1), 13-35.

Macdonald, S. J. (2003). Museums, National, Postnational and Transcultural Identities. Museum and society, 1 (1): 1-16.

Martín-Barbero, J. (2000). El futuro que habita la memoria. En Museo, memoria y Nación. Misión de los museos nacionales para los ciudadanos del futuro (pp. 33-63). Bogotá: Ministerio de Cultura y Museo Nacional de Colombia.

Martínez-Novo, C. (2011). Multiculturalismo oficial en América Latina: ¿democratización o consolidación de las desigualdades? En M. Chaves (Comp.). La multiculturalidad estatalizada. Indigenas, afrodescendientes y configuraciones del Estado (pp. 27-39). Bogotá: ICANH.

Meza, C. A. (2011). Patrimonialización cultural y desarrollo regional. La situación de los pueblos afrochocoanos en la vía al Mar. En M. Chaves (Comp.). La 
multiculturalidad estatalizada. Indigenas, afrodescendientes y configuraciones del Estado (pp. 255-265). Bogotá: ICANH.

Ministerio de Cultura. (2010). Compendio de politicas culturales. Bogotá: Ministerio de Cultura.

Múnera, A. (2005). Fronteras imaginadas. La construcción de las razas y de la geografía en el siglo XIX colombiano. Bogotá: Planeta.

Museo Nacional de Colombia (2012). Del Monumento al pensamiento. Patrimonio de Colombia para la humanidad. Recuperado el 14 de junio de 2013, de http:/ / www.museonacional.gov.co/sitio/patrimonio/exposicion.html

Navarro, O. (2006). Museos nacionales y representación: ética, museología e historia. Recuperado el 24 de marzo de 2013, de http://www.ilam.org/ ILAMDOC/MuseosRepresentacion.pdf

Olson, D. R. (1998). El mundo sobre el papel: el impacto de la escritura y la lectura en la estructura del conocimiento. Barcelona: Gedisa.

Restrepo, E. (2004). Biopolítica y alteridad: más allá del etnicismo y la multiculturalidad (neo) liberal. En E. Restrepo y A. Rojas (Eds.). Conflicto e (in) visibilidad. Retos en los estudios de la gente negra en Colombia (pp. 271-299). Popayán: Universidad del Cauca.

Rojas, A. y Castillo, E. (2005). Educar a los otros. Estado, politicas educativas y diferencia cultural en Colombia. Cali: Universidad del Cauca.

Salcedo, A. (2011). Desplazamiento y políticas públicas en Colombia, 19962006. En M. Chaves (Comp.). La multiculturalidad estatalizada. Indigenas, afrodescendientes y configuraciones del estado (pp. 281-294). Bogotá: ICANH.

Therrien, M. (2011). Los dilemas de las politicas culturales de patrimonialización en Colombia. En M. Chaves (Comp.). La multiculturalidad estatalizada. Indigenas, afrodescendientes y configuraciones del estado (pp. 239-253). Bogotá: ICANH.

Unesco. (2010). Nomination File No. 00436 for Inscription on the Representative List of the Intangible Cultural Heritage in 2010. Nairobi: Convention for the Safeguarding of the Intangible Cultural Heritage. Recuperado el 11 de junio de 2013, de http://www.unesco.org/culture/ich/index. php?lg=es\&pg $=00011 \& R L=00436$

Urizar, G. (2008). Símbolos de una Nación deseada. Museos nacionales y la construcción de la identidad nacional como política de Estado. En A. Leizaola y J. M. Hernández (Comps.). Miradas, encuentros y críticas antropológicas (pp.217-219). Recuperado el 24 de marzo de 2013, de http://www.ankulegi. org/wp-content/uploads/2012/03/130404Urizar.pdf

Wade, P. (1997/1993). Gente negra, nación mestiza. Dinámicas de las identidades raciales en Colombia. Bogotá: Universidad de Antioquia, ICAN, Siglo del Hombre y Universidad de los Andes.

Wade, P. (2002/2000). Música, raza y nación. Música tropical en Colombia. Bogotá: Vicepresidencia de la República de Colombia. 
Wade, P. (2004). Los guardianes del poder: biodiversidad y multiculturalidad en Colombia. En E. Restrepo y A. Rojas (Eds.). Conflicto e (in)visibilidad. Retos en los estudios de la gente negra en Colombia (pp. 249-269). Cali: Universidad del Cauca.

Wolf, E. (1987). Europa y la gente sin historia. México: Fondo de Cultura Económica. 